\title{
An Empirical Investigation on Work-Life Balance among Telecom Employees: Emerging HRM Interventions With Reference To Nokia Siemens Networks \& Ericsson Telecommunications
}

\author{
S. Vijaya Kumari ${ }^{1}$, Dr. A. Manor Selvi ${ }^{2}$ \\ ${ }^{\mathbf{1}}$ Research Scholar, St. Peters University-Avadi \\ ${ }^{2}$ Assistant Professor, St. Peters University-Avadi
}

\begin{abstract}
In India changing societal attitudes, inflation and rising educational levels made more people than ever before to drive into the paid workforce. The Indian employee, who were confined only to the socially acceptable jobs like banks, teaching, nursing etc., are now stepping into various sectors. Managing work and family responsibility can be very difficult for the telecom sector employees. Professional person especially telecom sector employees has to perform multiple roles in balancing their work life and personal life. Each role has its own set of demands and when such role demand overlaps/interacts, an imbalance is created leading to stress, attrition, absenteeism etc. Thus, there is an increasing need for organizations to address these demands of employees by implementing innovative HR policies. Work-life balance is one such HR practice that enables the employees particularly telecom employees to give proper prioritization between work and life roles. Hence, work-life balance has become a growing concern in both Public and Private sectors. The present paper based on empirical work, provides a deep insight of work-life balance of telecom sector employees in Private sector. An experimental sample has taken in 2 telecom sector equally. These sectors were evaluated on 6 sub scales viz: personal factors, balancing factors, organizational support, motivational factors, career advancement and psychological factors. The results reveal the picture of difficulties faced in balancing the work demand and the life (family) responsibility. There was high correlation between the difficulties faced and the balancing act to be performed. The significant results reflected in the areas of career advancement factors, organizational support and Psychological factors. The study defines certain specific HRM interventions for better work-life balance, per se.
\end{abstract}

Keywords: work life balance, HRM

\section{Introduction}

Liberalization, extending Privatization and Globalization policy has created a drastic change in an Indian economy in the past twenty years.15 Labor market has witnessed increasing employment opportunities, creating a way for young talented manpower, changes in demographic profile of employees, high pressurized jobs, opportunities to travel abroad, creation of dual career families etc., But on the other side of the coin employee is becoming much more ambitious, career oriented neglecting other aspects of life outside work.

Private sectors are the business sectors that are privately owned and not part of the government. They are intended to earn a profit for owners of the enterprise. Having different working environment, work timings, nature of work etc., both these sectors value the necessity of work life balance to the employees. In this paper an attempt has been made to study the effectiveness of work-life balance among telecom employees reflecting the age factor that influence and have repercussion in work-life balance paradigm by having a look at private sectors.

The Indian Telecom Sector has emerged as one of the critical components of economic growth required for overall socio-economic development of the country as there is a Positive correlation between the penetration of mobile services and internet on the growth of GDP of a country.
According to Joshi (2014), World Bank believes that an increase in mobile and broad band penetration increases the per capita GDP by $0.81 \%$ and $1.38 \%$ respectively in the developing countries. After post-liberalization, exponential growth on Telecom Sector in India can be seen, which actually helped the country for its economical development, (Nasit, 2011).

According to Earnst andYoung (2011), Indian telecom is an economic miracle in the making. They said that connecting such a vibrant economy of more than a billion people together and with the rest of the globe is an extraordinary achievement in terms of a nation's socioeconomic development. According to Shah (2008), the development of the Telecom Sector of India has experienced a major process of transformation in terms of its growth, technological content and market structure in the last decade through policy reforms introduced by Government of India. The sector has under gone a dramatic transformation from the government monopoly to a competitive environment after liberalization, where multiple private players could enter and started giving services to customers.

According to Tarab (2012), the joint effort of Government and private players of this sector has improved a lot and on its way of growth and development. Active participation of the private companies, foreign direct investment, sequence of reform measures initiated by the Government and wireless technology- played an important role in 


\section{International Journal of Science and Research (IJSR) \\ ISSN (Online): 2319-7064}

Index Copernicus Value (2013): 6.14 | Impact Factor (2014): 5.611

phenomenal growth of the sector in the country. It has become a very essential service, needed for rapid growth and modernization of various sector of the countryes economy

\section{Concept of Work-Life Balance}

Work-life balance is not mere related to work and life; it is the positive state of mind. Work-life balance, in its broadest sense, is defined as a satisfactory level of involvement or ,fit ${ }^{e c}$ between the multiple roles in a person's life (Hudson, 2005). Work-life balance is about the interaction between paid work and other activities, including unpaid work in families and community, leisure and personal development. Greenhaus, Collins \& Shaw (2003) defined work-family balance as "the extent to which an individual is equally-self engaged and equally satisfied with -his or her work role and family role". Work-life balance does not mean an equal balance in units of time between work and life. It is not a tight rope walk between two poles acting as an organizational commitments and home demands at the same time, but it is about proper understanding of the priorities of the professional and personal level.

\section{HRD-Work Life Balance}

Managing a home while raising young children when both spouses are employed outside the home is challenging and stressful .Balancing one"s work responsibilities and desires with one best, challenging. While balancing work commitments with life commitments involves a myriad of trade-offs for twoincome families with children, it also provides ongoing challenges for adults who remain single or do not have children.

Mid-life workers often deal with balance issues from two ends of the spectrum: young children and ageing parents. This issue, however, includes employees beyond those who have children. Many employees are choosing to stay unmarried, but still have critical and valuable commitments outside work. Individuals affected by trying to balance work and their lives outside work represent nearly the entire working population.

Organizations are indeed helping their workforce achieve balance between work and the rest of their life. Work-life balance programs are pervasive in organizations today i.e on-site day care ,elder-care assistance, flexible scheduling, job sharing, adoption benefits, on-site summer camps, petcare and even lawn care for employees who travel. It is time to move the issue beyond programs to instill a way of thinking throughout corporations on the need for balancing work and life successfully and equitably.

HRD professionals, the developers of people, are in a unique position to facilitate the transformation from providing employees with helpful programs to recognizing and rewarding employees who are able to work hard and effectively but still maintain a satisfying life outside work. Specific actions are articulated that human resource development professionals can demonstrate to drive the change. Human resource developers, who are charged with developing the workforce, must get involved in the transformation campaign. Work-life integration is not strictly a human resource management issue; it is an organizational effectiveness issue and HRD has the opportunity to play a key role.

HRD is able to take on this challenge because it has demonstrated a track record of delivering results. For years, HRD has been paramount in developing either program intended to meet the personal development needs of individuals or programs that were required by everyone to build a critical capability within the organization Additionally, HRD has been extremely successful in bringing to the workplace life enhancement skills, such as money management, wellness training and career planning These programs are intended to address the personal interests and needs of individuals within organizations.

\section{Research Design}

An organization is said to be competitive and economically sustainable in the market if it delivers quality goods and consistency in results. It is not just enough for them for simply employing and paying the people. Working environment will be effective when there is work life imbalance. The researcher thrown light in these issues and made some attempts to understand what motivates the employees and drives them towards job satisfaction. The results revealed employees generally expect not only appropriate and competitive pay for the work they perform but also hope to achieve a balance between work and rest of their lives. After considering various views from the collected literature reviews research design was formed. It includes the need for the present study, specific objectives of the study, hypothesis of the study, scope and variables of the study, methodology and sampling, statistical tools adopted in the study and also the limitations and presentation of the study.

\section{Review of Literature}

Considerable research has highlighted the fact that work-life balance is an important indicator of organization development. The research work by Susi.S and Jawaharrani.K (2010) explains how work-life balance and employee engagement becomes a visible benchmark among high performing organizations. The study indicated, many family-friendly organizations feel the need for work-life balance which includes recruitment and retention of valuable work force, reduced absenteeism, reduced employee stress, health benefits, job satisfaction, and better life balance. The study suggested that an effectiveness of work-life balance policies and practices must incorporate the effects of workplace culture and supervisor support of employeees efforts to balance work and family responsibilities.

Chawla and Sondhi (2011) in their survey conducted among teachers and BPO women professionals revealed that job autonomy and organizational commitment are in positive relation with work-life balance. The study indicated that the more proactive schools/BPO companies which value the contribution of a committed and contributing human resource will need to provide more autonomy to sustain their employee's work-life balance. While work load and work

\section{Volume 4 Issue 12, December 2015}




\section{International Journal of Science and Research (IJSR) \\ ISSN (Online): 2319-7064}

Index Copernicus Value (2013): 6.14 | Impact Factor (2014): 5.611

family conflict indicated negative relation with work-life balance.

Shanti and Sundar (2012) in their study of work-life balance of women employees in IT21 industry analyzed that programs implemented by IT firms of Chennai satisfy different categories of employees differently. Data were collected from 350 women employees working in various IT companies .The study measured the satisfaction levels of the respondents across various work-life balancing parameter. $55 \%$ of the employees were highly satisfied with the current work-life initiatives.

Ignacia Levy (2012) in his study of working mothers and their perceived work-life balance showed that the age of the children is not that significant but the child-care support remains an important factor in determining perceived worklife balance. The study also highlighted another parameter called role conflict having negative impact on work-life balance.

Pandu., et al (2013) analyzed work-life balance of professional women among IT and ITES based on demographic information, work load, work environment, feelings about work, family dependants and absence from work. The sector wise regression analysis demonstrated that feelings about work, family dependants and absence from work are the strong contributors for a sense of balance for an employee. However, no significant relationship has been obtained between work environment and work life balance.

Madipelli. et al (2013) in their research on factors causing work-life imbalance among schoolteachers showed that most of the teachers feels stress with too many work demands, working conditions and long working hours. The multiple roles played by women at work place and home reflecting boredom, frustration and stress lead to work-life imbalance. Marital relationship, attitude, co-operation of husbands and family members are highly influencing factors which create imbalance among working women.

The study of Ajith. et al (2013) on work-life balance for role prioritization of IT employees showed that the employees were able to fulfill their professional and personal commitments at the same time, because of better work-life balance policies. The relationship between work-life balance policies and role prioritization was significant. The study was conducted on variables like travelling time, depression, temper, work etc., to know the relation between work-life balance and stress management.

\section{Objectives of the Study}

- To study the nature and significance of human resources and the policies and procedures of HR in telecom sector employees

- To find out the procedures and Facilities of Work life balance of telecom employees

- To examine the perceptions of respondents on specific areas of work life balance telecom sector

- To analyze the effectiveness of work life balance in two companies namely nokia Siemens network solutions \& ERICSSON
- To asses and evaluate the impact of work life balance of employees and Suggest the specific recommendations for the betterment.

\section{Hypotheses}

1) Demographic groups do not have an influence on Work life Balance of employees.

2) Impact of family support on Work Life Balance of employees is not Influenced by demographic groups.

3) Impact of family hindrances on Work Life Balance of employees is not influenced by demographic groups.

4) Job satisfaction of employees has no significant influence on their Work Life Balance.

5) The influence of Job performance on Work Life Balance is not influenced with demographic groups.

6) Job Autonomy has no significant influence on Work life Balance of employees with varying demographic groups.

\section{Methodology and Sampling}

The study is based on both primary and secondary information and data. The main sources of secondary data are the annual reports and bulletins of the respective enterprises. The HRD/personnel departments of the select units have been used as the potential source of information relating to work life balance aspects. The seminar papers presented and articles published by executive of the enterprises have been found useful to get the information and data for the study. A structured questionnaire has been used as an important tool to collect the primary data from the sample respondents of the two select organizations namely NOKIA SIEMENS NETWORK SOLUTIONS and ERICSSON. The questionnaire collected some broad Areas of Work-Life balance perspective.

A pilot survey was conducted using the blue print of questionnaire and 10 respondents each of the select Undertakings were chosen to administer the questionnaire before circulating them to the target group. The interpretations of both primary and secondary data are made with the help of simple and weighted averages. Where ever the sample respondents stated the preferences/ranks of variables, these variables are assigned the weights in descending order. The response of the sample respondents on the dimensions of Work Life Balance were taken with various options like High- Moderate- Low, Always-OftenSometimes-Never, Excellent-Good-Satisfactory-Poor, etc. Thus, the present study has collected a total sample of 230 employees randomly, out of which 110 from NOKIA SIEMENS NETWORK, 120 from ERICSSON, which constitute the 5 percent of the total employees segment.

\section{Statistical Method Adopted in the Study}

Primary data were entered using SPSS (Statistical Package for Social Sciences) software and STATISTICA. Uni-variate and bi-variate tables were generated and F-tests and t-tests were carried out for testing the hypotheses. The object of the F- test is to find out whether the two independent estimates of population variance differ significantly, or whether the two samples may be regarded as drawn from the normal populations having the same variance.

\section{Volume 4 Issue 12, December 2015}




\section{Limitations of the Study}

This study has acknowledged some limitations. The participants in this study are employees of two organizations i.e. NOKIA SIEMENS SOLUTIONS \& ERICSSON the findings may not be generalized to other populations. The reason being no data and information has maintained by the respective departments of the organizations to measure the work life balance with the family commitments, the investigator has concluded with the available data. Similarly some employees were not willing to disclose their personal or family matters which could not be assessed for want of recorded data and information. Inconsistency in the responses is another limitation. For cross check purposes certain items are repeated in the questionnaire and the element of inconsistency removed.

\section{Major Findings And Suggestions}

1) Out of the total respondents 78 percent expressed their ability to balance their work in their organization on the other 22 percent of them are not confident to balance their work in any manner. It is suggested to insist the employees in selected organizations and to create awareness about the importance of work life balance.

2) In NSN and ERICSSON 82-74 percent of respondents expressed positively or confident to balance their routine work smoothly/comfortably. It is suggested that the management of selected organizations take necessary steps to overcome their inhibition and motivate them to enhance their personality and performance.

3) Majority of Respondents (57 percent) from both NSN and ERICSSON expressed the travelling hours for them are less than one hour followed by 1-3 hours (29 percent) are spending on their daily travelling, Due to some personal reasons like employees are residing far from the company, inadequate transport facilities to reach their work spots.

4) It is understood that out of the total sample, 110 respondents in NSN, 120respondents in ERICSSON, are depressed sometimes and 16 respondents in NSN and 30 respondents in ERICSSON opined that they are always depressed; the reason might be the lack of coordination among employees, personal and family problems carried to the work spot. It is suggested that the employers should take care of the wellbeing and provide ecofriendly environment by encouraging informal and social gathering when ever required, if possible the select organizations may provide periodical counseling to the employees and make them to overcome from their work imbalance.

5) It is a known fact that stress can be reduced through some sort of entertainment, as a part most of the employees in NSN preferred meditation is the criterion for reducing their stress, but employees in ERICSSON shown limited interest towards meditation. It is suggested by all means

Management should inculcate the belongingness among employees and arrange stress reducing activities like get together, cultural/recreational programmes as and when required.

\section{Conclusion}

It is concluded from the perception of the sample respondents both NSN and ERICSSON, a good number (8274 percent) of respondents expressed positively or confident enough to balance their routine work smoothly/comfortably. Due to some economic, family problems, inefficiency, lack of commitment some of the sample respondents (18 percent in NSN, 26 percent in ERICSSON) expressed their inability to balance their work and it is also proved that the significant level in NSN is high on some of the practices like working hours, flexible stating time, present hours of work, amount of wage earned by the employees, and training given to the employees and compulsory overtime.

Hence it is concluded that NSN employees are more satisfied with all the above practices than ERICSSON employees. Therefore it is suggested that the management of selected organizations to plan and take necessary steps to overcome the inhibition and motivate them to enhance their personality and performance by providing stress reducing activities like rest rooms for relaxation, social meetings, workers participation, refreshment as and when necessary, recreational facilities, regular breaks, superior and subordinate relations childcare and eldercare, Periodical counseling for healthy and productive environment. Thus, managing and organizing both work and life of employees systematically and strategically in any public or private sector units have led to enhanced productivity in the long run.

\section{References}

[1] Ajith,Madhu and Vidya.S.Patil (2013), "An Empirical Study On Work Life Balance For Role Prioritization of IT Employees", RVIM Journal of Management Research, 5(1) : 31-40.

[2] Chawla,Deepak and Neena Sondhi (2011), "Assessing Work-Life Balance Among Indian Women Professionals", The Indian Journal of Industrial Relations, 47(2): 341-351.

[3] Francis, Valerie and Helen Lingard (2004), “A Quantitative Study of Work Life Experiences inthe Public and Private sectors of the Australian Construction Industry", Published by Construction Industry Institute Australia Inc., Melbourne University.

[4] Greenhaus, J.H, Collins,K.M. and Shaw, J.D(2003), "The Relation Between Work -Family Balance and Quality of Life", Journal of Vocational Behaviour,63:510-531.

[5] Hewlett,Sylvia Ann (2002), "Executive Women and the Myth of Having It All", Harvard Business Review, April, 80(4): 66-73.

\section{References}

[1] www.askjeeves.com

[2] www.citehr.com

[3] www.sciencedirect.com

[4] www.google.com 